\title{
Consciousness of dairy farmers about leptospirosis disease as a zoonosis
}

\author{
SJ Jadav ${ }^{1}$ and JK Patel ${ }^{2}$
}

Received: 06 June 2021 / Accepted: 28 June 2021 / Published online: 07 September 2021

(C) Indian Dairy Association (India) 2021

\begin{abstract}
The study was carried out to assess the consciousness of dairy farmers about leptospirosis disease as a zoonosis. Using the simple random sampling method, 180 dairy farmers from 36 villages of 6 talukas of Panchmahals and Mahisagar districts of Gujarat state (India) were selected. The majority of dairy farmers (88.34 per cent) had medium to high level of consciousness about leptospirosis disease. The majority of the dairy farmers had very low to low level of knowledge (83.89 per cent), very high level of sensitivity (62.78 per cent) and favorable to most favorable attitude ( 95.55 per cent) towards the control of leptospirosis disease as a zoonosis. The relationship between education, extension participation, mass media exposure, internet exposure, professional training received, scientific orientation, innovation proneness and economic motivation of dairy farmers with their consciousness on leptospirosis disease were found to be a positive and significant. Dairy farmers can enhance their consciousness about leptospirosis disease through participation in different extension activities with using mass media, internet and other psychological variables.
\end{abstract}

Keywords: Attitude, Consciousness, Dairy farmers, Knowledge, Leptospirosis, Sensitivity, Zoonosis

\footnotetext{
${ }^{1}$ Dairy Vigyan Kendra, SMC College of Dairy Science, Anand Agricultural University, Anand-388110, Gujarat, India Email: sanjay.jadav89@gmail.com
}

${ }^{2}$ Extension Education Institute, Anand Agricultural University, Anand, Gujarat, India

Email: jkpatelaau@gmail.com

Sanjay J Jadav ( $\square)$

Dairy Vigyan Kendra, SMC College of Dairy Science, Anand Agricultural University, Anand-388110, Gujarat.

Email: sanjay.jadav89@gmail.com; Mobile no. 9662748360

\section{Introduction}

Leptospirosis is one type of zoonotic disease caused by Leptospira bacteria excreted in the urine of infected animals, such as rodents, livestock, and domestic pets (Bharti et al. 2003). Leptospirosis can occur through direct contact of an infected animal or indirect contact with an environment contaminated with the urine of infected animals (Levett, 2004). Symptoms of leptospirosis disease range from a mild flu-like illness to more severe complications such as jaundice, hemorrhage, meningitis, and renal dysfunction (Bharti et al. 2003). Leptospirosis outbreaks are mostly at the coastal regions of the states of Maharashtra, Tamil Nadu, Gujarat, West Bengal, Karnataka, Kerala, Orissa, and the Andaman Islands. Leptospirosis occurs highest from October to November, which coincides with the monsoon season in these parts (Himani et al. 2013). Recently, Leptospirosis has considerable significance being progressively involved in cases of abortions, repeat breeding, and other reproductive problems and resulted in huge livestock economic losses. In humans, Leptospirosis is associated with a mild fever to severe jaundice and death due to multi-organ failure (Srivastava and Kumar, 2003).

This obviously implies that dairy farmers must be educated to acquire higher level of consciousness and technical skills to prevent and control of leptospirosis disease to avoid economic losses as well as animal and human health hazards. The above facts would substantiate the need for creating consciousness among the group of animal keepers. Hence greater emphasis should be laid on educating animal keepers, particularly on sustainable animal productivity with substantial and judicious use of technologies that prevent and control leptospirosis disease as a zoonosis. One way extension scientists can contribute to this task to find out better ways and means for promoting the consciousness about leptospirosis disease among the clientele group. Since the change in knowledge and attitude precede sensitivity in preventing and controlling leptospirosis disease, it is always important to find out the most influential factors of changing farmers' knowledge about leptospirosis disease, molding positivism towards its control and their sensitivity. Unfortunately this type of research has not been 
conducted in the study area. The study will be helpful to policy makers in developing concrete strategies to prevent \& control leptospirosis.

\section{Materials and Methods}

\section{Study area}

The present study was conducted in Panchmahals and Mahisagar districts of Gujarat state (India) between the periods of August to October 2020. Panchmahals district has total of seven talukas (Godhra, Halol, Kalol, Jambughoda, Shehera, Morwa (Hadaf) and Ghoghamba). Panchmahals district lies between 22.45 Northern latitudes and 73.36 Eastern longitudes. Mahisagar district consists of 6 talukas (Balasinor, Lunawada, Kadana, Virpur, Santrampur and Khanpur). Mahisagar district geographically lies between 23.13 Northern latitudes and 73.62 Eastern longitudes. Paddy and maize are the predominant crops of Panchmahals and Mahisagar districts.

\section{Study design}

Three talukas each were selected from Panchmahals district and Mahisagar district based on the higher bovine population. Six villages from each taluka were selected randomly. Five dairy farmers were selected from each village randomly.

\section{Survey instruments}

The independent variables of this research study were measured with the help of appropriate scales used by other researchers with due modification. To measure the consciousness of dairy farmers, a standardized scale was developed by the researcher, which has three components viz., Knowledge about leptospirosis disease, sensitivity towards leptospirosis disease and attitude towards control of leptospirosis disease as a zoonosis. Consciousness means that the state of being awake, aware of what is around, and able to think. Consciousness is a term used to describe the awareness of one's physical and mental experience (Tononi and Koch, 2015). Rogers and Shoemaker (1971) considered knowledge as a function of an innovation-decision process when "the individual is exposed to an innovation existence and gains some understanding of its functions." Sensitivity means the capacity of an individual to respond to stimulation according to Merriam-Webster Dictionary. Attitude refers to the degree of positive or negative feelings of an individual associated with any object (Thurstone, 1946).

Knowledge about leptospirosis disease and attitude towards control of leptospirosis disease were measured with the help of scale developed by the researcher, and sensitivity towards leptospirosis disease was measured by teacher made scale.

\section{Knowledge, Attitude and Sensitivity score}

In case of knowledge score aspect, a weightage of 1 was assigned to the correct answer, and for an incorrect answer, a weightage of " 0 " was assigned. The possibility to get the knowledge scores ranged from 0 to 16 for an individual. To know the knowledge score of dairy farmer sum of the score of each item was obtained. In relation to sensitivity score, the scores of 1 and 0 were assigned for right and wrong response attributed by a dairy farmer, respectively. There were a total of seven statements for leptospirosis. The possibility to get the scores ranged from 0 to 7 for an individual. For the attitude score aspect, out of the 11 selected statements, ten statements were positive and had indicators of favorable attitude and one statement was negative and had unfavorable attitude. Items related to attitude were measured on a Likert scale ranging from 1 to 5 ( 1 = strongly disagree to $5=$ strongly agree), with higher scores indicating the most desired attitude.

\section{Data analysis}

Respondents were categorized into very low, low, medium, high and very high categories for knowledge level and sensitivity level with help of arbitrary method. Coefficient of correlation (r) was calculated to find out the relationship between each of the independent variables and dependent variable. The data were collected with the help of pre-tested Gujarati version interview schedule by personal interview and then after it was compiled, tabulated, and analyzed to get a proper answer for the specific objectives of the study with the help of various appropriate statistical tools. SPSS 21 (IBM, USA) was used to process the collected data.

\section{Results and Discussion}

\section{Computation of consciousness index}

In order to compute weightage values for each of the identified components, their relative importance to the overall consciousness was obtained by seeking experts' judgment.

The identified components were circulated among 50 experts working in the relevant specified field in the agricultural universities. Keeping in mind the importance of a particular component, they were asked to distribute 100 scores among the selected three components. The weightage of the particular component assigned by each expert was summed up, and the arithmetic mean calculated and rounded off the nearest integral

Table 1 Component wise weightage of consciousness

\begin{tabular}{llc}
\hline Sr. No. & Components of consciousness & Weightage \\
\hline 1 & Knowledge & 39.56 \\
2 & Sensitivity & 28.24 \\
3 & Attitude & 32.20 \\
& Total & 100.00 \\
\hline
\end{tabular}


figure. Thus, the component-wise weightage is shown in Table 1.

The consciousness of dairy farmers about leptospirosis disease was determined by using the following formula.

$$
\begin{array}{r}
\text { Consciousness index }=(\mathrm{R} 1 / \mathrm{M} 1) \times \mathrm{W} 1+(\mathrm{R} 2 / \mathrm{M} 2) \times \mathrm{W} 2+(\mathrm{R} 3 / \\
\mathrm{M} 3) \times \mathrm{W} 3
\end{array}
$$

Where,

$\mathrm{CI}=$ Overall consciousness index of dairy farmers about leptospirosis disease

$\mathrm{R} 1, \mathrm{R} 2, \mathrm{R} 3=$ Score obtained by the respondent for the particular consciousness indicator

M1, M2, M3 = Potential score of the respondent for a particular consciousness indicator

$\mathrm{W} 1, \mathrm{~W} 2, \mathrm{~W} 3$ = Relative weight value of the particular consciousness indicator

Knowledge of dairy farmers about leptospirosis disease is divided into five sub parts like general part of disease, transmission route, symptoms of animal, symptoms of human and prevention \& control aspect. The mean percentage score for knowledge was
22.71 (SD: 3.46). It can be observed in Table 2 that only 30.00 per cent of the dairy farmers had knowledge that leptospirosis is a zoonotic disease. Majority of the dairy farmers did not know about the meaning of zoonosis. A few dairy farmers (32.22 per cent) had knowledge about susceptibility of leptospirosis disease to bovine animals. A contrast finding was reported by Mathanamohan et al. (2020) and revealed that farmers were able to identify cows \& buffaloes (70.80 per cent) as vectors for leptospirosis in the district of Colombo, Sri Lanka. Two-fifth (40.00 per cent) of the dairy farmers had known that rats as a major source of leptospirosis. Arulmozhi and Natarajaseenivasan (2017) revealed that only less than 20.00 per cent participants were aware about transmitting agent rat. Very few dairy farmers had knew about transmission of leptospirosis through drinking contaminated water, infected animal urine and contaminated soil $\&$ mud (14.44 per cent), and abrasions or cuts in skin, intact skin after prolonged immersion in contaminated water and infected bulls or AI (11.67 per cent). A contrary finding was observed by Abdullah et al. (2019) and indicated that majority of respondents (71.4 per cent) thought modes of transmission of leptospirosis were through contaminated food and drinks. Very less per cent of dairy farmers had knowledge about symptoms of animal \& human suffering from leptospirosis. More than half (61.11 per cent) of the dairy farmers had knew about prevention of leptospirosis through avoid contact with rodents followed by

Table 2 Knowledge level of dairy farmers about leptospirosis disease

$(n=180)$

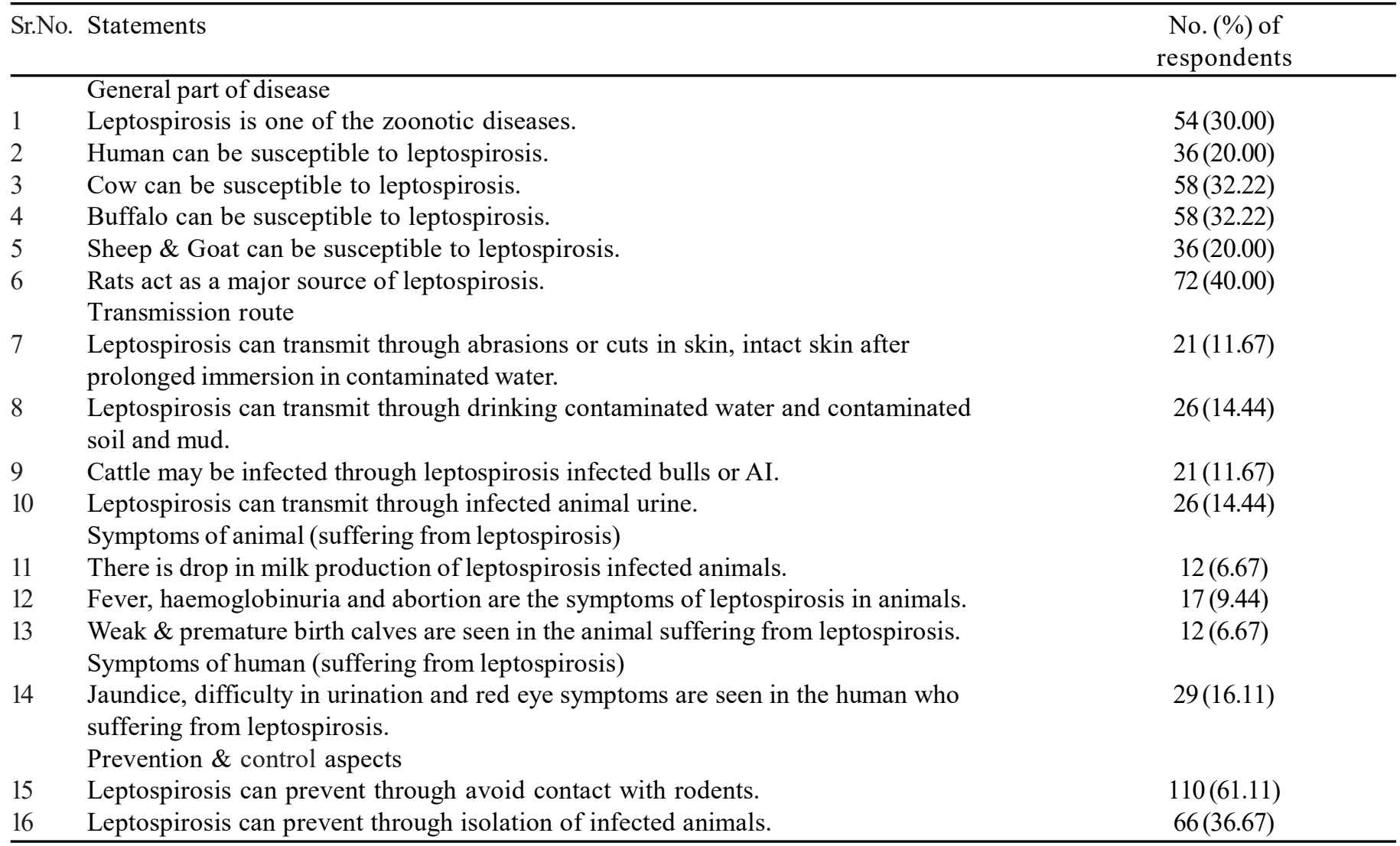


isolation of infected animals (36.67 per cent). Mathanamohan et al. (2020) reported that less than one-third ( 65.80 per cent) of the farmers knew rodent control was a preventive measure for leptospirosis in the community which was similar to the findings of this study.

More than half (56.11 per cent) of the dairy farmers had very low level of knowledge about leptospirosis (Table 3 ). The majority of dairy farmers (83.89 per cent) had very low to low level of knowledge about leptospirosis. The reason behind of this result was low prevalence rate of leptospirosis disease in the study area. A similar finding was reported by Arulmozhi and Natarajaseenivasan (2017), but in contrast with the result was reported by Bhabhor (2020).

Majority (62.78 per cent) of the dairy farmers had very high level of sensitivity towards leptospirosis, followed by 18.89, 16.11, and 2.22 per cent of them had medium, high and low level of sensitivity about leptospirosis (Table 3 ). None of them had very low sensitivity towards leptospirosis. The mean percentage score for sensitivity was 82.70 (SD: 1.42). A similar finding was reported by Prabhu et al. (2014); Arbiol et al. (2016).

More than half( 60.55 per cent $)$ of the dairy farmers had favorable attitude towards control of leptospirosis disease, followed by 35.00 and 4.45 per cent of them had most favorable and neutral attitude towards control of leptospirosis disease. None of them had most unfavorable or unfavorable attitude towards the control of leptospirosis disease as a zoonosis (Table 3). A similar finding was observed by Prabhu et al. (2014); Abdullah et al. (2019); Mathanamohan et al. (2020) and reported that majority of the respondents had satisfactory attitude towards leptospirosis disease. The mean percentage score for attitude was 78.08 (SD: 5.17). The detailed analysis of sensitivity of dairy farmers towards prevent leptospirosis is described in Table 4.

The detailed analysis of attitude of dairy farmers towards control of leptospirosis as a zoonosis is described in Table 5. From the

Table 3 Knowledge, Sensitivity \& Attitude level of the dairy farmers about leptospirosis $(n=180)$

\begin{tabular}{|c|c|c|c|}
\hline Sr.No. & Knowledge category & Frequency & Per cent \\
\hline$\overline{1}$ & Very low (up to 20.00 per cent) & 101 & 56.11 \\
\hline 2 & Low (20.01 to 40.00 per cent) & 50 & 27.78 \\
\hline 3 & Medium (40.01 to 60.00 per cent) & 12 & 6.67 \\
\hline \multirow[t]{2}{*}{5} & Very high (above 80.00 per cent) & 5 & 2.77 \\
\hline & Total & 180 & 100.00 \\
\hline 2 & Low (20.01 to 40.00 per cent) & 4 & 2.22 \\
\hline 3 & Medium (40.01 to 60.00 per cent) & 34 & 18.89 \\
\hline 4 & $\operatorname{High}(60.01$ to 80.00 per cent $)$ & 29 & 16.11 \\
\hline \multirow[t]{2}{*}{5} & Very high (above 80.00 per cent) & 113 & 62.78 \\
\hline & Total & 180 & 100.00 \\
\hline 4 & Favorable (60.01 to 80.00 per cent) & 109 & 60.55 \\
\hline \multirow[t]{2}{*}{5} & Most favorable (above 80.00 per cent) & 63 & 35.00 \\
\hline & Total & 180 & 100.00 \\
\hline
\end{tabular}

Table 4 Sensitivity of dairy farmers towards prevent leptospirosis

$(\mathrm{n}=180)$

\begin{tabular}{llc}
\hline Sr. No. & Statements & $\begin{array}{c}\text { No. (\%) of } \\
\text { respondents }\end{array}$ \\
\hline 1 & Sensitive regarding the effect of leptospirosis on human health & $154(85.56)$ \\
2 & Sensitive regarding using poison or traps to eradicate rats & $140(77.78)$ \\
3 & Sensitive to keep the feedstock of animals in sealed or rodent-proof containers & $136(75.56)$ \\
4 & Sensitive to follow allopathic treatment for leptospirosis affected animals & $145(80.56)$ \\
5 & Sensitive to keep the animal shed \& premises disinfected properly & $155(86.11)$ \\
6 & Sensitive to take more care when fever, blood in urine, or milk was noticed & $153(85.00)$ \\
7 & Sensitive to keep animals suffering leptospirosis away from the rest of the herd & $159(83.33)$ \\
\hline
\end{tabular}


Table 5 Attitude of dairy farmers towards control of leptospirosis as a zoonosis ( $\mathrm{n}=180)$

\begin{tabular}{|c|c|c|}
\hline Sr. No. & Statement & $\begin{array}{c}\text { Mean } \\
\text { Percent Score }\end{array}$ \\
\hline 1. & I believe that leptospirosis disease can be eradicated from our country $(+)$ & 80.44 \\
\hline 2. & I feel that leptospirosis disease is hazardous to human health $(+)$ & 84.44 \\
\hline 3. & $\begin{array}{l}\text { There is a lot of propaganda about the leptospirosis disease, but it is not so in a real } \\
\text { situation. }(+)\end{array}$ & 73.56 \\
\hline 4. & I would like to purchase leptospirosis disease-free animals for my farm $(+)$ & 79.89 \\
\hline 5. & $\begin{array}{l}\text { I believe that leptospirosis disease is the current burning issue to handle seriously in dairy } \\
\text { farming }(+)\end{array}$ & 73.00 \\
\hline 6. & I believe that the sale of animals infected with leptospirosis disease is ethical $(-)$ & 64.22 \\
\hline 7. & I feel that constant monitoring is needed to control leptospirosis disease $(+)$ & 79.89 \\
\hline 8. & Leptospirosis disease-infected animals affect badly dairy farm income. $(+)$ & 81.78 \\
\hline 9. & $\begin{array}{l}\text { I believe that leptospirosis disease can be successfully controlled through managemental } \\
\text { practices }(+)\end{array}$ & 80.22 \\
\hline 10 & I feel that control of leptospirosis disease should be a prime goal of veterinary public health $(+)$ & 80.00 \\
\hline 11. & I believe that public awareness regarding leptospirosis disease is the need of hours $(+)$ & 81.44 \\
\hline
\end{tabular}

+ Positive statement, - Negative statement

Table 6 Dairy farmers according to their consciousness about leptospirosis disease $(n=180)$

\begin{tabular}{lllc}
\hline Sr. No. & Category & Frequency & Per cent \\
\hline 1 & Very low (up to 20.00 per cent) & 0 & 0.00 \\
2 & Low (20.01 to 40.00 per cent) & 11 & 6.11 \\
3 & Medium (40.01 to 60.00 per cent) & 100 & 55.56 \\
4 & High (60.01 to 80.00 per cent) & 59 & 32.78 \\
5 & Very high (above 80.00 per cent) & 10 & 5.55 \\
& Total & 180 & 100.00 \\
\hline
\end{tabular}

Table 7 Relationship between characteristics of dairy farmers and their consciousness about leptospirosis disease

\begin{tabular}{lll}
\hline $\begin{array}{l}\text { Sr. } \\
\text { No. }\end{array}$ & Characteristics & $\begin{array}{l}\text { Correlation } \\
\text { Coefficient } \\
\text { ('r' value) }\end{array}$ \\
\hline 1 & Age & $0.016^{\mathrm{NS}}$ \\
2 & Education & $0.456^{* *}$ \\
3 & Dairy farming experience & $0.008^{\mathrm{NS}}$ \\
4 & Family size & $-0.056^{\mathrm{NS}}$ \\
5 & Landholding & $0.117^{\mathrm{NS}}$ \\
6 & Herd size & $0.076^{\mathrm{NS}}$ \\
7 & Annual income & $0.104^{\mathrm{NS}}$ \\
8 & Social participation & $-0.048^{\mathrm{NS}}$ \\
9 & Extension participation & $0.355^{* *}$ \\
10 & Mass media exposure & $0.422^{* *}$ \\
11 & Internet exposure & $0.268^{* *}$ \\
12 & Professional training received & $0.290^{* *}$ \\
13 & Scientific orientation & $0.319^{* *}$ \\
14 & Innovation proneness & $0.259^{* *}$ \\
15 & Economic motivation & $0.196^{* *}$ \\
$16^{\mathrm{a}}$ & Attitude with knowledge level & $0.152^{*}$ \\
$17^{\mathrm{a}}$ & Attitude with sensitivity level & $0.161^{*}$ \\
$18^{\mathrm{a}}$ & Knowledge with sensitivity level & $0.120^{\mathrm{NS}}$ \\
\hline
\end{tabular}

* Significant at 0.05 per cent level of probability, ** Significant at 0.01 per cent level of probability, NS nonsignificant, acorrelation between components of consciousness result of this study it is revealed that leptospirosis disease can be successfully controlled through managemental practices $(80.22$ MPS) and constant monitoring (79.89 MPS). A similar finding was observed by Prabhu et al. (2014); Mathanamohan et al. (2020) and reported that majority of the respondents had positive attitude towards importance of gloves during work.

Perceived human health hazards effect of leptospirosis as a zoonotic disease on animals and human beings by the dairy farmers as well as economic losses caused by such a disease was the major reasons for the formation of positivism toward control of leptospirosis disease might be the possible explanation for this result.

The majority ( 55.56 per cent) of dairy farmers had medium level of consciousness about leptospirosis disease, followed by 32.78 per cent high consciousness about leptospirosis disease. There was 6.11 per cent and 5.55 per cent low and very high level of consciousness about leptospirosis disease. None of them had very low level of consciousness about leptospirosis disease (Table 6). Knowledge of the dairy farmers about leptospirosis disease as a component of consciousness is still to work for enhancing consciousness level of dairy farmers regarding leptospirosis disease as a zoonosis. Mathanamohan et al. (2020) stated that the knowledge, attitudes and practices and identifies gaps which 
need to be addressed for effective prevention of leptospirosis in the farming community. So, knowledge is the important component of consciousness which have positive relationship with attitude and sensitivity.

The Pearson correlation analysis was conducted to identify the relationship between factors affecting the consciousness of dairy farmers about leptospirosis and independent variables. In Table 7 , out of fifteen independent variables, eight variables viz., education, extension participation, mass media exposure, internet exposure, professional training received, scientific orientation, innovation proneness and economic motivation had established a positive and significant relationship with the consciousness of dairy farmers about leptospirosis disease. The result shows that the consciousness of dairy farmers about leptospirosis was significantly increasing with increase in education, participation in extension activities \& training programmes, exposure of mass media $\&$ internet with scientific orientation, innovation proneness and economic motivation. Correlation between attitude level with knowledge level (0.152) and sensitivity level $(0.161)$ of dairy farmers regarding leptospirosis was found to be positive and significance at 5 per cent. There is no relationship between knowledge level and sensitivity level of dairy farmers about leptospirosis. Arbiol et al. (2016) indicated that knowledge and attitudes about leptospirosis, gender and broadcast media were significant factors for leptospirosis prevention practices that were common to both agricultural and non-agricultural workers which were similar to the findings of this study and also reported by Manlapaz et al. (2019) and stated that a significant relationship between knowledge and attitude as well as attitude and practice however, not bearing significant relationship knowledge and practice on leptospirosis.

\section{Conclusions}

The majority of dairy farmers had medium to high level of consciousness about leptospirosis disease. The majority of dairy farmers had very low to low level of knowledge about leptospirosis disease and had very high level of sensitivity with favorable to most favorable attitude towards control of zoonotic diseases. There is a need to organize special programmes to improve the knowledge on leptospirosis as zoonosis to enhance the consciousness of dairy farmers and general people about leptospirosis disease and their impact on animals and humans' health through education and extension activities with using mass media, internet and other psychological variables. Those variables which had established significant influence on the consciousness of dairy farmers about leptospirosis as a zoonosis must be reckoned while planning any programme related to zoonoses.

\section{References}

Abdullah NM, Mohammad WMZW, Shafei MN, Sukeri U, Idris Z, Arifin WN, Nozmi N, Saudi SNS, Samsudin S, Zainudin AW, Hamat RA, Ibrahim R, Masri SN, Saliluddin SM, Daud A, Osman M, Jamaluddin TZMT (2019) Leptospirosis and its prevention: knowledge, attitude and practice of urban community in Selangor, Malaysia. BMC Public Health 19: 628

Arbiol J, Orencio PM, Romena N, Nomura H, Takahashi Y, Yabe M (2016) Knowledge, Attitude and Practices towards Leptospirosis among Lakeshore Communities of Calamba and Los Baños, Laguna, Philippines. Agriculture 6: 18

Arulmozhi T, Natarajaseenivasan K (2017) Knowledge, Attitude and Practices Related to Leptospirosis among Risk population in periphery of South Chennai in India. Int J Adv Res Biol Sci 4: 183187

Bhabhor IN, Vyas HU, Patel NR (2020) Knowledge of livestock farmers about various zoonotic diseases. Guj J Ext Edu 31: 92-94

Bharti A, Nally J, Ricaldi J, Matthias M, Diaz M, Lovett M (2003) Leptospirosis: A zoonotic disease of global importance. Lancet Infect Dis 3: 757-771

Himani D, Suman MK, Mane BG (2013) Epidemiology of leptospirosis: an Indian perspective. J Foodborne Zoonotic Dis 1: 6-13

Levett PN (2004) Leptospirosis: A forgotten zoonosis? Clin Appl Immunol Rev 4: 435-448

Manlapaz JV, Ganotisi GVH, Ferrer MKL, Cruz JCD, Eclevia KNL, Diquino AA, Gimenez SYL, Enderez CJV, Rosario DD (2019) Level of knowledge, attitude, and practice on Leptospirosis among residents in a selected community in Quezon city, Phillipines. Ann Trop \& Public Health 22: S352B

Mathanamohan J, Kaleel F, Hyderaly H, Imthiyaz I, Unais R, Nisansala T, Weerasekera M, Fernando N, Liyanage T, Gunasekara C (2020) Farmers' occupational health, perception and practices towards leptospirosis: A cause for concern. Sri Lankan J Infect Dis 10:21-29

Prabhu N, Meera J, Bharanidharan G, Natarajaseenivasan K, Ismail M, Uma A (2014) Knowledge, Attitude and Practice towards Leptospirosis among municipal workers in Tiruchirapalli, India. Int J Pharm Res Health Sci 2: 246-254

Rogers EM, Shoemaker FF (1971) Communication of Innovation: A Cross Cultural Approach. New York, Free Press: 476

Srivastava SK, Kumar AA (2003) Seroprevalence of Leptospirosis in animals and Human beings in various regions of country. Indian J Comp Microbiol Immunol Infect Dis 24: 155-159

Thurstone LL (1946) Comment. Am J Sociol 52: 39-50

Tononi G, Koch C (2015) Consciousness: here, there and everywhere? Phil Trans R Soc B 370: 20140167 